\title{
THE PRAGMATICS OF REFUSING A REQUEST IN ITALIAN AND AMERICAN ENGLISH: A COMPARATIVE STUDY
}

\author{
Massimo Verzella and Laura Tommaso
}

\begin{abstract}
This study falls in the area of cross-cultural pragmatics because it compares how speakers of American English and speakers of Italian refuse a request. We used a guided conversation protocol to elicit refusals to a request. The results show marked differences between the two groups. Speakers of American English tend to rely on Positive face strategies (praise, encouragement) to mitigate their refusals. In contrast, speakers of Italian tend to use Negative face strategies: lengthy explanations combined with apologies. Both groups used avoidance strategies, but speakers of American English were less likely to offer detailed explanations that require the disclosure of personal information. These findings show that pragmatic strategies to perform speech acts might vary significantly even when we compare groups from two different Western countries.
\end{abstract}

\section{Keywords}

cross-cultural pragmatics, politeness, refusing, guided conversation, American English, Italian

\section{Introduction}

Refusals are difficult speech acts to perform due to their face-threatening nature (Brown \& Levinson 1987). The possibility of offending the hearer is inherent in the act itself. For this reason, speakers need to develop their pragmatic competence to avoid unintended offense and breakdowns in communication. The purpose of our research was to compare how speakers of American English and speakers of Italian realize the speech act of refusing a request. As far as we know, comparative research on American-English and Italian refusal strategies has never been conducted within the theoretical frame of cross-cultural pragmatics.

Our research focus is on how politeness is conveyed linguistically: Leech (2014: 13) calls this subdomain in politeness studies "pragmalinguistics" to distinguish it from "sociopragmatics", which focuses on the social and cultural determinants of politeness. Contrastive pragmalinguistics, Leech explains, "analyzes and compares the linguistic resources available, and their use, in different languages" (ibid.: 14). As we designed our study, we preferred to use the word comparative, instead of contrastive because we did not want to assume that 
we would find significant differences in the way our two groups of respondents realize the speech act of refusing.

To avoid confusion, it is also important to distinguish between cross-cultural and intercultural research in both linguistic and communication studies. Our study is cross-cultural in that we collected data in two cultures and compared them. The respondents from the US never interacted with the respondents in Italy. In contrast, intercultural studies ask respondents from different cultures to meet and interact so that investigators might analyze how different habits and communication practices might affect their interaction (Kecskes 2017).

We believe that comparative studies on how speakers of different languages refuse requests have important implications for language teaching. Reflecting on the professional needs of learners, Eslami (2010: 217) states: "Due to the complex nature of this speech act and the inherent risk in offending someone, there is a strong need for pragmatic instruction in order to help learners interpret and realise this speech act successfully". Grammar rules and generic communicative competence do not help much when a situation necessitates the selection of the most appropriate way to perform specific speech acts like requesting or refusing. From this perspective, studies on the pragmatics of refusing can significantly enhance learners' ability to use a foreign language in effective ways. Social workers and mediators can also greatly benefit from this research since they are constantly looking for ways to build stronger relationships between people of all backgrounds.

\section{Politeness theory: A brief overview}

A key area of research within the study of pragmatics is politeness. The development of linguistic politeness theories has been stimulated by Austin's (1962) and Searle's (1979) theory of speech acts, Goffman's theory of facework (1955, republished in Goffman 1967), and Grice's (1975) work on conversational implicatures. We owe early conceptualizations of politeness theory to Lakoff (1973), Brown and Levinson (1978, 1987), and Leech (1983). Of the three theories, Brown and Levinson's became the most influential even if it clearly shows an Anglocentric bias. Their model is based on the idea that politeness is a universal feature of all human languages. Every socio-cultural group will aim at cooperative interaction while placing significant value on consideration for others.

All studies of politeness include reflections on the concept of face. We follow Leech (2007: 199) in understanding face as "the self-image or self-esteem that a person maintains as a reflection of that person's estimation by others". A negative face goal is "the goal of avoiding loss of face"; a positive face goal is "the goal 
of enhancing face". Negative politeness is used to mitigate possible causes of offence (Leech 2014: 11), or the degree to which speakers' goals are imposed on hearers. Strategies frequently used to achieve negative face goals typically include the use of indirectness and hedging. In contrast, positive politeness "gives or assigns some positive value to the addressee" (ibid.: 12), and calls for the use of compliments, congratulations, thanks-yous, and even apologies.

Before moving on to the speech act of refusing, it is important to add that the Anglo-Western bias of politeness theories has often been criticized by scholars committed to relativistic positions. Scholars from China and Japan criticized the emphasis on individualistic goals and values that runs through Brown and Levinson's theorizations; an emphasis that is at odds with the more group-centred ethos of Eastern societies (Ide 1989, Matsumoto 1989, Gu 1990, Mao 1994). To address the problem of the Anglocentric bias of the conceptual tools used in politeness theory and research, a group of scholars led by Goddard (1989a, 1989b) and Wierzbicka (1991) proposed to eliminate terms like face, distance, or indirectness to explain interactional meaning. Terms borrowed from English, they suggest, create a terministic screen that distorts the interpretation of verbal interactions enacted in cultures that do not belong to the Western group. To approach the study of pragmatics from a culture-independent point of view, they propose the use of a "natural semantic metalanguage" based on what they consider to be the universal core of natural languages.

We agree with Leech (2007) that it is time to move beyond the dichotomy between universalism and relativism. While it is true that politeness manifests itself in different terms in different languages and cultures, it is also true that a completely relativistic position would be at odds with research that identified common patterns in the understanding and performance of politeness.

\section{The speech act of refusal: Definitions}

Refusals often constitute the second part of adjacent pairs in verbal exchanges that start with an elicitation act (e.g. offers, invitations, and requests). Once hearers decide to turn down an offer or refuse a request formulated by the speaker, they need to decide how they will realize a speech act that is potentially face-threatening because it expresses a form of disapproval (Chen et al. 1995). In many cases, the illocutionary goal of refusing a request will compete with the social goal of maintaining a good relationship with people. For this reason, those who refuse will often use redressive action to mitigate the impact of their refusal and make amends for what could be seen as uncooperative behavior (Gass \& Houck 1999). As Eslami (2010: 217) explains, in response to requests or invitations, "acceptance is usually preferred and a refusal is disprefered [sic]". 
Dispreferred second actions are complex speech acts whose impact needs to be mitigated by quickly choosing the most appropriate repair strategies. It is always difficult to deal with a refusal for a speaker because hearers might be offended by what they might perceive as a sign of dislike (Takahashi \& Beebe 1987).

While the speech acts included in adjacent pairs like request/refusal or invitation/refusal threaten both self-face and other-face, scholars seem to agree that hearers tend to be more affected (Eslami 2010, Salazar Campillo et al. 2009) for two main reasons: First, hearers are asked to do what the speaker wants, not what they want. Second, hearers who refuse requests are called upon to perform a face-threatening act in a very short time. While refusals call for redressive actions that preserve both the negative and positive face of the hearer, Siebold and Busch (2015: 54) point out that those who refuse are often concerned about their own positive face. They explain that the Spanish students who participated in their research "found it difficult to openly reject something above all because they wanted to give a good impression to their interlocutors".

Similarly to what happens for other face-threatening acts, the amount of negotiations or repair work necessary to mitigate the effect of a refusal depends on social and situational variables (Brown \& Levinson 1987, Beebe et al. 1990). As they produce refusals, hearers will have to 1) consider the cultural factors that regulate politeness strategy in a given context; 2) select the most appropriate linguistic resources from the pragmatic repertoire offered by different languages. Cultural and social factors that influence the way in which refusals are encoded include distance between interlocutors in terms of power, horizontal distance (degree of familiarity), group affiliation, or the social value of what is being transacted. Among the linguistic resources, Leech (2007: 195-196) cites honorific forms, modal verbs, hedges, intensifiers, Self-reference forms and Other-reference forms (e.g. $t u$ and $l e i$ in Italian, $t u$ and vous in French), and omission of $1^{\text {st }}$ and $2^{\text {nd }}$ person reference in Japanese and Korean. Refusals are often accompanied by prefaces, hesitations or elements of delay (pauses, fillers), justifications, expressions of doubt, and apologies (e.g. Levinson 1983, Pomerantz 1984).

\section{The speech act of refusal: Comparative studies}

Studies of refusals are usually classified in two categories. Some researchers conduct interlanguage studies (Bardovi-Harlig \& Hartford 2005, Félix-Brasdefer 2017) to investigate the different ways in which native speakers of a global language (usually English) and learners of this global language realize refusals (Beebe et al. 1990, Widjaja 1997, Wannaruk 2008, Chang 2011, Al-Gahtani $\&$ Roever 2018). Others investigate how two (or more) groups of native speakers 
of different languages realize refusals while talking to other native speakers of their language. Our study belongs to the second category.

The most featured population in cross-cultural studies is native speakers of American English, whose strategies to refuse a request are compared to the strategies used by speakers of other languages. Using an open role-play situation as a data collection instrument, Félix-Brasdefer (2003) compared Latin American speakers of Spanish with Americans speaking Spanish and Americans speaking English. He found that, compared to the group of Latin American speakers, both groups of American speakers preferred to use positive opinion to mitigate their refusals. American speakers speaking English were also more direct than Latin American speakers of Spanish even in situations of unequal status. Félix-Brasdefer (2008) also studied refusals produced by people living in Mexico and people living in the Dominican Republic: He found that Mexicans use a wider range of refusal strategies than the Dominicans, whose strategies were employed in fewer and shorter turns. His research seems to support the idea that variation is to be expected across different cultures especially in terms of strategies for repair work.

Morkus (2014) also used role play to determine patterns and differences in the way in which speakers of Egyptian Arabic and speakers of American English realize refusals. In line with a study conducted by Al-Eryani (2007), he found that Arabic refusals tend to be less direct than American refusals. He also found that, in unequal status situations, Egyptians were more reluctant to use direct strategies for refusal. In contrast, speakers of American English did not seem to be too concerned about the social status of their interlocutor. Another important finding from Morkus' study (2014) is that Egyptians used two strategies to mitigate their refusals that Americans never used: The strategy of invoking the Name of God and the strategy of Proverb/Common Saying, which shows how Egyptians prefer to use fixed, almost ritualistic, expressions to save face.

Working with the language pair Korean/American English, Kwon (2004) found that Koreans tend to refuse more indirectly and tentatively than speakers of American English. Korean speakers appeared to hesitate more frequently, and often paused and apologized before refusing. In contrast, English speakers relied on positive face strategies by expressing gratitude and praising ideas and initiatives. Kwon also found that Korean speakers tended to mitigate their refusals by offering explanations, a strategy that English speakers never used. Finally, Kwon's study shows that English speakers tend to be less concerned about power differences among people compared to speakers of other languages. Honglin (2007) reports similar findings in a study that focused on speakers of American English and speakers of Chinese. The Chinese participants appeared 
to use more indirect strategies to achieve their goal of restoring relationships between people. In contrast, speakers of American English used more direct strategies to solve the problems in question.

Working with the same language pair and using a data-completion test, Liao and Bresnahan (1996) found that their Chinese participants tended to use fewer tokens in refusing a request. The reason for their laconic style has to do with their concern for ending an awkward exchange as soon as possible. However, this refusal strategy might be misunderstood by Western negotiators in business, who might not be able to infer a refusal from a short apology or an apology combined with a brief explanation. Liao and Bresnahan also found that Americans often express positive opinion before refusing a request or an invitation. Instead, Chinese speakers rarely use formulas like "I'd like to" because "they are afraid that if they express positive opinions, then they will be forced to comply" (ibid.: 725).

Instead of using data-completion tests, Role play, or guided conversations, Ghazanfari et al. (2013) analyzed 50 Persian-language and 50 English-language films to investigate how speakers of these two languages refuse different types of speech acts (offers, requests, invitations, etc.). A finding that is particularly relevant for the present research is that Persian speakers utilized avoidance strategies (especially hedging and postponement) more than English speakers. In turn, English speakers appeared to be more direct, more open in their interactions, and more straightforward than Persian speakers, but they also tried to mitigate their refusal using more apologies and statements of regret than Persian speakers.

Most of these studies seem to support the idea that speakers from Western countries tend to use different politeness strategies than speakers of Eastern countries, even if these differences should not prompt scholars to speak in terms of an absolute divide between East and West (Leech 2007). Importantly, differences in the way in which people realize refusals can also be found by comparing Western cultures. For example, Siebold and Busch (2015) found differences in the way speakers of Spanish and speakers of German realize refusals. The Spanish speakers clearly preferred indirect refusal strategies that often included explanations, postponement, and expressions of insecurity. In contrast, German speakers tended to use supporting moves that can be labeled as appreciation formulas. This is a clear strategy of positive politeness that shows how German speakers are attentive to the positive face needs of their interlocutors.

Fewer studies have focused on how speakers of Italian realize refusals. Frescura carried out an exploratory research in 1997. Her ethnographic study of refusals to an offer of food provides insight into Italian speakers' language tactics as well as their cultural values, norms, and assumptions associated with 
food sharing and consumption. Frescura found that speakers of Italian rarely refuse an offer of food explicitly and firmly. Rather, they prefer to use indirect forms that are immediately followed by apologies or compliments for the quality of the food prepared. A much later study in the field of transcultural pragmatics has been carried out by Cortés Velásquez and Nuzzo (2017). Their study was designed to support the teaching of speech acts in Italian as a foreign language course. In particular, they focused on the strategies employed by Italian speakers to cancel an invitation and found that speakers of Italian tend to mitigate their refusals by using explanations combined with expressions of regret. Sometimes, explanations replace explicit cancellations. Less frequently, Italian speakers rely on offers of repair, which they convey by expressing their resolve to participate at another time.

\section{Methodology}

The goal of this study was to determine whether there is a significant difference in the way in which speakers of American English and speakers of Italian perform the speech act of refusing a request. Our hypothesis was that, using different types of redressive action, our two groups of respondents would mitigate the impact of their refusals.

\subsection{Participants}

This study took place at two different universities, one in Italy (Molise University or Unimol) and one in the US (North Dakota State University or NDSU). We recruited 50 students at both institutions. The age range of the participants at NDSU was 18-23. Randomly selected all over the NDSU campus, all participants were born and raised in Minnesota and North Dakota and were living in the Fargo-Moorhead area when the present study was conducted (2016). The age range of the participants at Unimol was 19-25. The participants, randomly selected, were all born and raised in the Southern-central Italy (regions of Campania and Molise).

\subsection{Instrument and procedure}

Much research on politeness relies on data-completion tests (DCTs). The problem with DCTs is that we cannot assume that people produce speech acts in the same way in both writing and speaking. Due to the absence of interlocutors whose face would be threatened by a refusal, completing a test is not a stressful situation. It is relatively easy to refuse a request when we are not facing our interlocutor(s) and when we have plenty of time to formulate a response. The 
situation becomes significantly more complicated when we have to produce a refusal under the strong time pressure of face-to-face conversation.

Considering that observation of authentic speech involves collecting spontaneous data in naturally occurring settings, a method that makes it possible to obtain more reliable information on politeness strategies is face-to-face guided conversation. According to Wolfson (1986), this data collection method is the most reliable in speech act research. This view is shared by other researchers (e.g. Olshtain \& Blum-Kulka 1985). Face-to-face guided conversations are greatly reliable because they allow to capture what speakers actually say rather than what they think they would say in a given speech situation (Hartford \& Bardovi-Harlig 1993, Golato 2003, Kasper 2008).

There was no difference in social status between our research collaborators (undergraduate students at the two universities), who formulated the requests, and the students who refused the requests. To reduce the effects of the "observer's paradox" (Labov 1972) - which occurs when participants realize that they are being studied, and, for this reason, control or monitor their answers - our collaborators started the guided conversations by asking the participants if they had international friends. After a short conversation on international students and diversity at NDSU and Unimol, our collaborators asked the participants if they were willing to join an organization of native speakers who met three times a week to have conversations with international students interested in improving their skills in spoken English (at NDSU) and spoken Italian (at Unimol). We named these student organizations respectively the Conversational English Circle (CEC) and Gruppo Conversazione in Italiano (GCI). The goal of the guided conversations was to elicit refusals from the participants by placing emphasis on the fact that the members of the CEC would have to meet three times a week for two hours at a time.

We classified the speech act realized by the speakers as a request because, in offers and invitations, speakers propose to do something for the benefit of hearers (Leech 2014: 180). As Blum-Kulka et al. (1989: 12) observe, requests impose mainly on the hearer and call for mitigation to compensate for their impositive effect. By joining the CEC, the hearers would contribute to the success of an initiative that they did not contribute to organizing. While hearers could certainly benefit from joining an international circle of students, they were asked to commit a lot of their time when they clearly had other priorities like studying, completing assignments, and preparing for tests. 


\subsection{Taxonomy of refusals}

For the sake of data analysis, we distinguish between refusals that lack redressive action and refusals that use redressive action. Within the category of refusals that use redressive action, we developed three categories:

- Redressive action that focuses on positive face

- Redressive action that focuses on negative face

- Avoidance (indirect refusals)

When we noticed that all the refusals that we collected used different combinations of the following strategies, we developed other subcategories inductively:

- No (or other types of direct refusal)

- Positive opinion

- Explanation

- Apology

Our subcategories were developed to obtain a more fine-grained picture of the relationship between the main redressive action selected by the participants and the specific strategies that they used to produce the speech act of refusing. Instead of constraining data into predetermined categories, we allowed our taxonomy to emerge from the refusals. Once we started to analyze our data, we discovered that participants had not used several different strategies to mitigate the impact of their words. Instead, many of their strategies appeared to overlap significantly. A group of participants seemed to prefer positive politeness by assigning positive value to the addressees and their idea of creating a CEC (or GCI). This group produced the refusal in two main ways: Some started with a direct negation, then mitigated the impact of their refusal by praising the initiative. Others preferred to save their interlocutor's face by starting with words of praise for the initiative, and then explaining why they had to refuse. The second group of participants resorted to negative politeness by focusing more on self-face. In other words, their focus was on maintaining their own face rather than enhancing their interlocutor's face. This group produced the refusals in three ways: Some boldly used the word no before sharing personal problems that did not allow them to join the CEC/GCI. Others preferred to soften their use of no with apologies. Finally, some participants avoided saying no by creatively combining apologies and explanations.

Taxonomies of refusal strategies cannot be exhaustive because politeness can be realized in many different ways, depending on linguistic, situational, social, and cultural factors. We did not include strategies such as hesitation, gratitude, or postponement because we consider them ancillary to the main strategies that 
we inductively identified. In the corpus of refusals that we collected, hesitation, gratitude, and postponement were always used to complement the participants' main rhetorical goal. They were never used in isolation because their function was to accompany positive opinion and explanations or add an element of uncertainty to the refusal.

When compared to more detailed classifications, such as the one proposed by Beebe et al. (1990), our taxonomy is less fine-grained but more generalizable and less likely to cause disagreement between coders. Instead of trying to capture endless nuances in semantic formulas for refusing - an endeavor that would be far from objective - we classified the refusals based on the primary emphasis of the speech act performed. The problem is that, unless they are realized in laconic ways, refusals can often be hybrid in nature. Speakers who rely mostly on positive face can still use words or body language that indirectly convey an apology. Similarly, speakers who prefer negative face can hint at the value of an initiative while still placing emphasis on explanation and the "protection" of self-face. Different refusal strategies can always overlap a bit, but the main strategy for redressive action is usually clear.

By relying a bit less on complex classifications based on the English language, we tried to disentangle politeness research from Anglo-Western traditions and move towards a more culture-independent analytical framework. Table 1 below shows the taxonomy that we used to classify the refusals produced during the guided conversations. The examples below are prototypical simplified refusals that are not taken from the data elicited. The prototypical refusals are given first in English, then in their Italian equivalents.

\begin{tabular}{|c|c|c|}
\hline Refusals strategies & Example: English & Example: Italian \\
\hline \multicolumn{3}{|l|}{$\begin{array}{l}\text { Refusal without redressive } \\
\text { action }\end{array}$} \\
\hline $\begin{array}{l}\text { Blunt refusal: No or other } \\
\text { types of direct refusal }\end{array}$ & No/I can 't/I don't think so & No/non posso/non penso \\
\hline \multicolumn{3}{|l|}{$\begin{array}{l}\text { Refusal with redressive } \\
\text { action: positive face }\end{array}$} \\
\hline $\begin{array}{l}\text { No (or other types of direct } \\
\text { refusal) + emphasis on } \\
\text { positive opinion }\end{array}$ & $\begin{array}{l}\text { It's a great initiative, but I } \\
\text { can't come }\end{array}$ & $\begin{array}{l}\grave{E} \text { una ottima iniziativa, ma } \\
\text { non posso venire }\end{array}$ \\
\hline $\begin{array}{l}\text { Emphasis on positive opinion } \\
+ \text { Explanation }\end{array}$ & It's a great idea, but I'm busy & $\begin{array}{l}\grave{E} \text { una grande idea, ma sono } \\
\text { impegnato }\end{array}$ \\
\hline
\end{tabular}




\begin{tabular}{|l|l|l|}
\hline $\begin{array}{l}\text { Refusal with redressive } \\
\text { action: negative face }\end{array}$ & $\begin{array}{l}\text { No, I have a doctor's } \\
\text { appointment } \\
\text { direct refusal) + emphasis } \\
\text { on explanation }\end{array}$ & $\begin{array}{l}\text { No, ho un appuntamento dal } \\
\text { dottore }\end{array}$ \\
\hline $\begin{array}{l}\text { No (or other types of } \\
\text { direct refusal) + emphasis } \\
\text { on apology }\end{array}$ & I'm really sorry, but I can't & $\begin{array}{l}\text { Mi dispiace molto, ma non } \\
\text { posso }\end{array}$ \\
\hline $\begin{array}{l}\text { Explanation }+ \text { Apology } \\
\text { Avoidance }\end{array}$ & I'm too busy, I'm really sorry & $\begin{array}{l}\text { Sono troppo occupato, mi } \\
\text { dispiace veramente }\end{array}$ \\
\hline $\begin{array}{l}\text { Avoidance }+ \text { emphasis } \\
\text { on positive opinion }\end{array}$ & $\begin{array}{l}\text { It sounds like a good } \\
\text { initiative; I'll see if I can }\end{array}$ & $\begin{array}{l}\text { Sembra una bella iniziativa; } \\
\text { vedrò se posso }\end{array}$ \\
\hline $\begin{array}{l}\text { Avoidance }+ \text { emphasis } \\
\text { on explanation }\end{array}$ & $\begin{array}{l}\text { I'm busy, but I'll think about } \\
\text { it }\end{array}$ & $\begin{array}{l}\text { Sono impegnato, ma ci } \\
\text { penserò }\end{array}$ \\
\hline
\end{tabular}

Table 1: Taxonomy of refusals

\subsection{Data analysis}

In order to identify the strategies used by the participants, we followed Nelson et al. (2002) in dividing the refusals into idea units. For example, the refusal below was divided in two idea units:

Example 1:

It's a great idea, and I would like to join... but I'm too busy this semester

(i) It's a great idea (positive opinion)

(ii) and I would like to join (positive opinion)

(iii) but I'm too busy this semester (explanation)

In cases in which the participants responded with utterances containing several units and several strategies, we coded their speech act based on the primary emphasis of their refusal. For example, the refusal below was classified as No + emphasis on explanation:

Example 2:

Scusa, ma non posso davvero. Ho esami da preparare. Poi devo tornare a casa dai miei genitori ogni volta che posso. Sono super stressato.

(i) Scusa, ma non posso davvero. [I am sorry, but I really can't] (apology and direct refusal)

(ii) Ho esami da preparare. [I have to study for my exams] (explanation) 
(iii) Poi devo tornare a casa dai miei genitori ogni volta che posso. [Then I have to go back home to visit my parents whenever I can] (explanation)

(iv) Sono super stressato. [I'm really stressed out] (explanation)

In the utterance analyzed above, the primary strategy used for mitigation is explanation. While an apology is used, the speaker conducted most of her repair work by offering three different reasons why she could not join the GCI. Both the English and the Italian data were coded by the authors of the present study, who are near-native speakers of English and native speakers of Italian. In case of disagreement, the utterances were re-coded until consensus was reached. Our categories were exhaustive and mutually exclusive: All utterances were assigned to a specific category of our taxonomy, and all utterances could belong to only one category.

\section{Results}

As expected, speakers of American English and speakers of Italian never refused the request without some form of redressive action. American English speakers tended to mitigate their refusals with statements of positive opinion, whereas speakers of Italian tended to rely on explanations and apologies. Table 2 below offers a detailed picture of the results:

\begin{tabular}{|c|c|c|}
\hline Refusals strategies & $\begin{array}{l}\text { Number of speakers } \\
\text { of American English who } \\
\text { used this strategy (out of 50) }\end{array}$ & $\begin{array}{l}\text { Number of speakers } \\
\text { of Italian who used this } \\
\text { strategy (out of 50) }\end{array}$ \\
\hline \multicolumn{3}{|l|}{$\begin{array}{l}\text { Refusal without redressive } \\
\text { action }\end{array}$} \\
\hline $\begin{array}{l}\text { Blunt refusal: No or other } \\
\text { types of direct refusal (e.g. I } \\
\text { can't; I will not come) }\end{array}$ & 0 & 0 \\
\hline \multicolumn{3}{|l|}{$\begin{array}{l}\text { Refusal with redressive } \\
\text { action: positive face }\end{array}$} \\
\hline $\begin{array}{l}\text { No (or other types of direct } \\
\text { refusal) + emphasis on } \\
\text { positive opinion }\end{array}$ & 10 & 2 \\
\hline $\begin{array}{l}\text { Emphasis on positive opinion } \\
+ \text { Explanation }\end{array}$ & 8 & 3 \\
\hline $\begin{array}{l}\text { Refusal with redressive } \\
\text { action: negative face }\end{array}$ & & \\
\hline
\end{tabular}




\begin{tabular}{|l|l|l|}
\hline $\begin{array}{l}\text { No (or other types of direct } \\
\text { refusal) + emphasis on } \\
\text { explanation }\end{array}$ & 5 & 7 \\
\hline $\begin{array}{l}\text { No (or other types of direct } \\
\text { refusal) + emphasis on } \\
\text { apology }\end{array}$ & 4 & 5 \\
\hline Explanation + Apology & 4 & 10 \\
\hline Avoidance & 12 & 8 \\
\hline $\begin{array}{l}\text { Avoidance + emphasis on } \\
\text { positive opinion }\end{array}$ & 7 & 15 \\
\hline $\begin{array}{l}\text { Avoidance + emphasis on } \\
\text { explanation }\end{array}$ & & \\
\hline
\end{tabular}

Table 2: Results

When refusing a request in spoken conversation, speakers of American English do not use blunt refusals. Those who clearly refused the request, 36 per cent, used positive face strategies as a redressive action. In order to save their interlocutor's face, among those who preferred avoidance, 24 per cent still appeared to prefer positive opinion. The fact that this group preferred to use positive face and positive opinion shows that they did not see the speech act of requesting as particularly face-threatening. In other words, they did not treat the request as an obligation that they had to fulfill. For this reason, they dispreferred negative face strategies such as the use of explanations and apologies. Two examples of the use of the strategy No (or other types of direct refusal) + emphasis on positive opinion are reported below. The original utterances have been organized into idea units:

Example 3:

I can 't. But this is a great idea...I'm sure you'll find many people.

(i) I can't (direct refusal)

(ii) But this is a great idea... (positive opinion)

(iii) I'm sure you'll find many people. (positive opinion)

Example 4:

Probably not...it's nice of you to help international students. Thanks for the offer and what you do.

(i) Probably not... (direct refusal)

(ii) it's nice of you to help international students. (positive opinion)

(iii) Thanks for the offer and what you do. (positive opinion) 
The participants who did resort to explanations often stated that they were busy or offered just one reason why they could not join the Circle. Only two of the participants elaborated on the reasons why they could not join the CEC. The short explanations offered by this group of participants was often combined with praise for the initiative. Interestingly, four students used probably not to replace a more threatening no.

While the English speakers did not rely on avoidance as frequently as the Italian speakers did (38\% US vs. $46 \%$ ITA), they often used variations of the formula I'll think about it to evade the request. This avoidance strategy was more frequently combined with positive opinion than explanations, a result that confirms how speakers of American English are reluctant to justify their decision by making reference to personal problems or external factors.

Compared to speakers of Italian, speakers of American English were less likely to share personal information. This strategy seems to pertain to negative face because it allowed the participants to assert their independence and self-determination. This reticence to disclose personal information might be better understood once we see how negative face is related to Goffman's notion of territory (1967) and Brown and Levinson's (1987: 61) description of negative face as the basic claim to "territories" and "personal preserves". By refusing to elaborate their explanations, English speakers expressed what O'Driscoll (1996: 4) calls the "desire that the universal need for distance and individuation be given symbolic recognition in interaction".

In contrast to the North American participants, the Italian participants frequently relied on negative face strategies. The Italian participants tended to shift the conversation to their own problems and needs; i.e. they put themselves at the center of the exchange. Only 13 Italian speakers (26\%), as opposed to 30 speakers of American English (60\%), used positive opinion in their repair work, as if they felt that they had to concentrate on justifying themselves for the grievous offense of refusing. Compared to American speakers, who seemed more concerned about other-face, the Italian speakers were more inclined to see the act of refusing as affecting their own face. In other words, they saw themselves as more vulnerable than the person voicing the request. From this perspective, the type of repair work conducted by the Italian speakers appeared to be motivated by their need to minimize the threat to self-face that they perceived as inherent in the speech act of refusing a request. Perhaps it is for this reason that speakers of Italian used more intensifiers than speakers of American English.

An example of $\mathrm{No}+$ emphasis on explanation

Example 5:

Non posso proprio; (direct refusal; proprio is the intensifier) ho gli esami. (explanation) Devo studiare. (explanation) [I really can't; I have exams, I have to study] 
An example of No + emphasis on apology

Example 6:

No grazie; (direct refusal) mi dispiace davvero... (apology; davvero is the intensifier) scusa, (apology) ma non posso. (direct refusal) [No thanks; I am really sorry... forgive me, but I can't]

A refusal that combines explanation and apology

Example 7:

Questo purtroppo è un momento un po' particolare, (explanation) quindi non posso; mi dispiace tanto. (apology; tanto is the intensifier) [Unfortunately, this is a really tough moment, so I can't join; I am really sorry.]

Like their counterparts in the US, Italian speakers relied heavily on avoidance (46\%), but still tended to offer explanations, instead of positive opinion. Indeed, the most dramatic difference between speakers of American English and speakers of Italian was in the use of Avoidance + emphasis on explanation. Rather than placing emphasis on the value of the initiative, 30 per cent of the Italian participants combined postponement strategies and hesitation (e.g. non so, I don't know) with lengthy explanations and apologies to mitigate their refusals. The emphasis on explanation is particularly evident in the following example, which we classified as Avoidance + emphasis on explanation:

Example 8:

Original utterance by the Italian speaker organized into idea units:

(i) Non so... [I don't know...] (hesitation)

(ii) Ti dico la sincera verità, la proposta mi fa piacere. [I will tell you the honest truth, it is nice of you to make this proposal.] (gratitude)

(iii) Ma adesso... fra una ventina di giorni, mi sto per laureare; [But right now... in twenty days, I'm supposed to graduate;] (explanation)

(iv) quindi non so dopo che strada intraprendo. [so I don 't know what I'll do.] (explanation)

(v) Se ho un poco di tempo libero e sono disponibile magari si potrebbe anche fare; [ If I have some spare time, maybe I could join;] (postponement)

(vi) è una bella cosa... [it's a great thing...] (positive opinion)

(vii) sì... è da valutare insomma. [Yes... I need to think about it.] (postponement)

The example above (54 words, the longest refusal that we recorded) contains many different repair strategies, but even if there is an idea unit that functions as positive opinion and two that convey postponement, the main emphasis is on explanation. In this case, the main emphasis of the utterance was conveyed by means of paralinguistic signals such as speed and volume of delivery, pitch, and body language. The participant delivered the explanation part with greater emphasis: she slowed down, raised the volume and pitch of her utterance, frowned, and gesticulated more vehemently. The participant explained that she did not know what she would do after graduation, thus sharing with a stranger 
a very personal feeling of disorientation. This openness to disclose personal information appears to be a very distinctive trait of the way in which speakers of Italian refuse a request. Compared to speakers of American English, they appear to be less concerned about protecting their territory. The example above also shows how Italian speakers resorted to postponement to mitigate their rejection. The North-American participants also used postponement, but less frequently.

All in all, the utterances produced by speakers of American English were shorter than those produced by the Italian speakers. The average number of words used for the refusal was 17 for the North-American participants and 21 for the Italian participants. The participants in both groups of students were stopped and interviewed during weekdays when many of them were walking from one class to another. The difference in the average number of words used by the two groups cannot be explained by the fact that one group might have been more pressed for time than the other.

Even if, due to the different type of respondents recruited and the different methodology employed, our findings are not directly comparable to the findings of previous cross-cultural studies dealing with the same research question, our study does not contradict findings from previous studies on pragmatic strategies used by speakers of American English when refusing a request, an offer, or an invitation. This population tends to realize refusals more directly and with fewer hesitations and delays (hedging) than speakers of Spanish (Félix-Brasdefer 2003), Arabic (Morkus 2014), Korean (Kwon 2004) and Chinese (Honglin 2007). Just like speakers of German (Siebold \& Busch 2015) and in contrast with speakers of Chinese (Liao \& Bresnahan 1996), Italian, Korean, and Spanish, speakers of American English tend to rely on positive face strategies and appreciation formulas more than expressions of regret, apologies, and explanations. This last mitigation strategy, the formulation of lengthy explanations that attribute the refusal to external factors, appears to be typical of the Italian (Cortés Velásquez \& Nuzzo 2017) and Spanish pragmatic repertoire. Speakers of American English also appear to be more concise than both Italian and Spanish speakers, but not as laconic as speakers of Chinese (Liao \& Bresnahan 1996), who appear to be eager to move past the face-threatening situation.

While Americans occasionally rely on avoidance strategies, they rarely use postponement. In contrast, speakers of Persian (Ghazanfar et al. 2013), Italian, and Spanish often claim that they will reconsider the offer or request in the near future, thus leaving space for a change of heart or a possible acceptance. Based on these considerations, it can be hypothesized that, compared to speakers of Germanic languages, speakers of Romance languages are more likely to refuse by adopting negative face strategies like explanations and avoidance strategies 
like postponement. However, speakers of Italian seem to rely more on apologies and statements of regret compared to speakers of Spanish, an aspect that deserves further investigation. Even if Frescura (1997) focused on offers rather than requests, our findings do not contradict her claim that speakers of Italian rarely refuse offers explicitly and firmly, and tend to use apologies in their repair work.

\section{Conclusions}

Our findings show that speakers of American English and speakers of Italian tend to use different strategies when refusing a request. While respondents of both groups avoided the use of blunt strategies, redressive action was carried out in different ways. On the one hand, speakers of American English tended to reject the request using positive opinions; on the other hand, speakers of Italian relied more on explanations and apologies. The Italian speakers also used slightly more avoidance strategies than the English speakers.

While 70 per cent of the Italian participants used explanations and justifications, the North American participants employed this strategy less frequently (48\%). At an average utterance length of 17 words, the North American participants were more concise than the Italian speakers, who used an average of 21 words per utterance. The two groups also differed in the use of apologies, which appear to be a distinctive mark of the refusals formulated by the Italian speakers. In brief, North Americans were more straightforward in their refusals, but also cared to express positive opinion on the initiative, whereas Italians were more concerned to offer detailed explanations and apologies.

The Italian speakers' intention is more likely to be conveyed by strategies referring to the circumstances of their refusal (personal reasons and external factors). In contrast, the speakers of American English mitigated the impact of their more succinct refusals by praising the initiative illustrated by their interlocutor. Both groups relied on avoidance, but North Americans appear to be less likely to offer explanations that generally require the disclosure of personal information. One could tentatively argue that North Americans are slightly more direct (38\% used no or other direct refusals vs. $28 \%$ Italians) and explicit in their refusals, but also more reserved in the way they respond to requests. We also found it interesting that some Italian participants would transform the request into an offer so that they could kindly decline the offer, which they perceived as a less-threatening speech act. The participant who started his answer with No grazie [No thanks] appeared to cunningly manipulate the intention of the speech act produced by the interlocutor because it is ingrained in southern Italian culture that it is polite to decline offers. For example, there is a tacit expectation that dinner guests will decline offers for more food. It is for this reason that hosts will 
insist on making the same offer with increasing emphasis until the guests finally accept. As Example 4 shows, some English speakers also elaborated the request as an offer, but this move appeared to be less frequent in the English corpus of refusals.

A limitation of the present research is the fact that our participants belong to just one social group: college students. It would be important to repeat the same study with more diverse populations to introduce the variable of status. In addition, the way in which participants respond to requests should be compared to the way in which people respond to less impositive speech acts (offers and invitations, for example) that might elicit refusals. The social value of the transaction can also be manipulated in different ways to obtain a more fine-grained understanding of repair work conducted by hearers. Further limitations of this explorative study include the relatively small number of participants that we were able to recruit, which called for caution when it came to generalizing our results.

We believe that our findings can inform teaching and assessment of pragmatic competence in both English and Italian as second or foreign languages. Refusing in a foreign language is a complex communicative task that requires an in-depth understanding of both the sociocultural values and the pragmatic repertoire of the target culture and involves various strategies to avoid offending interlocutors. As recent findings in second language pragmatics research indicate (e.g. Eslami 2010, Taguchi \& Roever 2017), comparative research into the way in which members of different communities perform refusals and other speech acts leads to the development of more effective teaching materials. Based on the findings of research in cross-cultural pragmatics, it will also be possible to develop more effective programs for training people who work in cross-cultural teams; technical communicators, for example, but also social workers, teachers, interpreters and many other types of cultural mediators.

\section{Author attribution statement}

Massimo Verzella conducted the research project in the United States and wrote all sections of the paper. Laura Tommaso conducted the research project in Italy and contributed to write parts of the methods, results, and discussion sections of the paper. Verzella revised the manuscript upon receiving feedback from the editors and the two peer reviewers.

\section{Acknowledgements}

We thank Chiara Cicchese and Francesca D'Aloia (University of Molise), Brock Azure, Bailey Brazier, and Jacinta Thieschafer (North Dakota State University) for their contribution in the collection of data. 


\section{References}

Al-Eryani, A. A. (2007) 'Refusal strategies by Yemeni EFL learners.' Asian EFL Journal 19(2), 19-34.

Al-Gahtani, S. and Roever, C. (2018) 'Proficiency and preference organization in second language refusals.' Journal of Pragmatics 129, 140-153.

Austin, J. L. (1962) How to Do Things with Words. Cambridge: Harvard University Press.

Bardovi-Harlig, K. and Hartford, B. (eds) (2005) Interlanguage Pragmatics. Exploring Institutional Talk. Mahwah, NJ: Lawrence Erlbaum.

Beebe, L., Takahashi, T. and Uliss-Weltz, R. (1990) 'Pragmatic transfer in ESL refusals.' In: Scarcella, R., Andersen, E. S. and Krashen, S. D. (eds) Developing Communicative Competence in a Second Language. New York: Newbury House. 55-73.

Blum-Kulka, S., House, J. and Kasper, G. (1989) 'Investigating cross-cultural pragmatics: An introductory overview.' In: Blum-Kulka, S., House, J. and Kasper, J. (eds) Crosscultural Pragmatics: Requests and Apologies. Norwood, NJ: Ablex. 1-13.

Brown, P. and Levinson, S. C. (1978) 'Universals in language use: Politeness phenomena.' In: Goody, E. (ed.) Questions and Politeness: Strategies in Social Interaction. Cambridge: Cambridge University Press. 56-310.

Brown, P. and Levinson, S. C. (1987) Politeness: Some Universals in Language Usage. Cambridge: Cambridge University Press.

Chang, Y.-F. (2011) 'Refusing in a foreign language: An investigation of problems encountered by Chinese learners of English.' Multilingua 30(1), 71-98.

Chen, X., Lei, Y. and Zhang, Z. (1995) 'Refusing in Chinese.' In: Kasper, G. (ed.) Pragmatics of Chinese as Native and Target Language. Honolulu: University of Hawaii Press. 119-163.

Cortés Velásquez, D. and Nuzzo, E. (2017) 'Disdire un appuntamento: Spunti per la didattica dell'Italiano L2 a partire da un corpus di parlanti nativi.' Italiano LinguaDue $1,17-36$.

Eslami, Z. R. (2010) 'Refusals: How to develop appropriate refusal strategies.' In: Martínez-Flor, A., Usó-Juan, E. and Pearson, L. (eds) Speech Act Performance: Theoretical, Empirical and Methodological Issues. Amsterdam: John Benjamins. 217-236.

Félix-Brasdefer, J. C. (2003) 'Declining an invitation: A cross-cultural study of pragmatic strategies in American English and Latin American Spanish.' Multilingua 22(3), $225-255$.

Félix-Brasdefer, J. C. (2008) 'Sociopragmatic variation: Dispreferred responses in Mexican and Dominican Spanish.' Journal of Politeness Research 4(1), 81-110.

Félix-Brasdefer, J. C. (2017) 'Interlanguage pragmatics.' In: Huang, Y. (ed.) The Oxford Handbook of Pragmatics. Oxford: Oxford University Press. 416-434.

Frescura, M. (1997) 'Strategie di rifiuto in italiano: uno studio etnografico.' Italica 74(4), 542-559.

Gass, S. and Houck, N. (1999) Interlanguage Refusals: A Cross-cultural Study of Japanese-English. Berlin: Mounton de Gruyter.

Ghazanfari, M., Bonyadi, A. and Malekzadeh, S. (2013) 'Investigating cross-linguistic differences in refusal speech act among native Persian and English speakers.' International Journal of Research Studies in Language Learning 2(4), 49-63.

Goddard, C. (1989a) 'Issues in natural semantic metalanguage.' Quaderni di semantica $10(1), 55-64$. 
Goddard, C. (1989b) 'The goals and limits of semantic representation.' Quaderni di semantica 10(2), 297-308.

Goffman, E. (1955) 'On face work: An analysis of ritual elements in social interaction.' Psychiatry: Journal for the Study of Interpersonal Processes 18, 213-231.

Goffman, E. (1967) Interaction Ritual: Essays on Face-to-face Behavior. Garden City, NY: Anchor.

Golato, A. (2003) 'Studying compliment responses: A comparison of DCTs and recordings of naturally occurring talk.' Applied Linguistics 24(1), 90-121.

Grice, P. (1975) 'Logic and conversation.' In: Cole, P. and Morgan, J. (eds) Syntax and Semantics 3: Speech Acts. New York: Academic Press. 41-58.

Gu, Y. (1990) 'Politeness phenomena in modern Chinese.' Journal of Pragmatics 14(2), 237-257.

Hartford, B. and Bardovi-Harlig, K. (1993) 'Experimental and observational data in the study of interlanguage pragmatics.' In: Bouton, L. and Kachru, Y. (eds) Pragmatics and Language Learning, Monograph 3. Urbana-Champaign, IL: DEIL. 33-52.

Honglin, L. (2007) 'A comparative study of refusal speech acts in Chinese and American English.' Canadian Social Science 3(4), 64-67.

Ide, S. (1989) 'Formal forms and discernment: Two neglected aspects of universals of linguistic politeness.' Multilingua 8(2-3), 223-248.

Kasper, G. (2008) 'Data collection in pragmatics research.' In: Spencer-Oatey, H. (ed.) Culturally Speaking: Culture, Communication and Politeness Theory. London: Continuum. 279-303.

Kecskes, I. (2017) 'Cross-cultural and intercultural pragmatics.' In: Huang, Y. (ed.) The Oxford Handbook of Pragmatics. Oxford: Oxford University Press. 234-268.

Kwon, J. (2004) 'Expressing refusals in Korean and American English.' Multilingua 23(4), 339-364.

Labov, W. (1972) Sociolinguistic Patterns. Philadelphia: University of Pennsylvania Press.

Lakoff, R. (1973) 'The logic of politeness; or, minding your p's and q's.' In: Corum, C., Smith-Stark, T. and Weiser, A. (eds) Papers from the Ninth Regional Meeting. Chicago Linguistic Society. Chicago. 292-305.

Leech, G. (1983) Principles of Pragmatics. London: Longman.

Leech, G. (2007) 'Politeness: Is there an East-West divide?' Journal of Politeness Research 3(2), 167-206.

Leech, G. (2014) The Pragmatics of Politeness. Oxford: Oxford University Press.

Levinson, S. C. (1983) Pragmatics. Cambridge: Cambridge University Press.

Liao, C. and Bresnahan, M. J. (1996) 'A contrastive pragmatic study on American English and mandarin refusal strategies.' Language Sciences 18(3-4), 703-727.

Mao, L. M. (1994) 'Beyond politeness theory: Face revisited and renewed.' Journal of Pragmatics 21, 451-486.

Matsumoto, Y. (1989) 'Politeness and conversational universals: Observations from Japanese.' Multilingua 8(2-3), 207-221.

Morkus, N. (2014). 'Refusals in Egyptian Arabic and American English.' Journal of Pragmatics 70, 86-107.

Nelson, G. L., Carson, J., Al Batal, M. and Bakary, W. E. (2002) 'Cross-cultural pragmatics: Strategy use in Egyptian Arabic and American English refusals.' Applied Linguistics 23(2), 163-189.

O'Driscoll, J. (1996) 'About face: A defense and elaboration of universal dualism.' Journal of Pragmatics 25(1), 1-32. 
Olshtain, E. and Blum-Kulka, S. (1985) 'Degree of approximation: Nonnative reactions to native speech act behavior.' In: Gass, S. and Madden, C. (eds) Input in Second Language Acquisition. Rowley, MA: Newbury House. 303-325.

Pomerantz, A. (1984) 'Agreeing and disagreeing with assessments: Some features of preferred/dispreferred turn shapes.' In: Atkinson, J. and Heritage, J. (eds) Structures in Social Action: Studies in Conversation Analysis. Cambridge: Cambridge University Press. 57-101.

Salazar Campillo, P., Safont-Jordá, M. P. and Codina-Espurz, V. (2009) 'Refusal strategies: A proposal from a sociopragmatic approach.' RceL: Revista Electrónica de Lingüística Aplicada 8, 139-150.

Searle, J. (1979) Expression and Meaning: Studies in the Theory of Speech Acts. Cambridge: Cambridge University Press.

Siebold, K. and Busch, H. (2015) '(No) need for clarity. Facework in Spanish and German refusals.' Journal of Pragmatics 75, 53-68.

Taguchi, N. and Roever, C. (2017) Second Language Pragmatics. Oxford: Oxford University Press.

Takahashi, T. and Beebe, L. M. (1987) 'The development of pragmatic competence by Japanese learners of English.' JALT Journal 8(2), 131-155.

Wannaruk, A. (2008) 'Pragmatic transfer in Thai EFL refusals.' Regional Language Center Journal 39(3), 318-337.

Widjaja, C. (1997) 'A study of date refusals: Taiwanese females vs. American females.' University of Hawaii Working Papers in ESL 15(2), 1-43.

Wierzbicka, A. (1991) Cross-cultural Pragmatics. The Semantics of Human Interaction. Berlin: Mouton de Gruyter.

Wolfson, N. (1986) 'Research methodology and the question of validity.' TESOL Quarterly 20(4), 689-699.

Massimo Verzella is Assistant Professor of English Composition at Penn State Erie, The Behrend College. He received a Ph.D. in Rhetoric, Writing and Culture from North Dakota State University. His main areas of interest are in cross-cultural pragmatics, intercultural communication, writing pedagogy, and translation.

Address: School of Humanities and Social Sciences, Penn State Erie, The Behrend College 4701 College Drive Erie, PA 16563, USA. [muv56@psu.edu]

Laura Tommaso is a Lecturer of English language and literature at the University of Molise, Italy. She received a Ph.D. in English from "G. D'Annunzio" University (Pescara, Italy). Her areas of research encompass media discourse, multimodality, English language teaching, cross-cultural rhetoric, and the discourse of aging.

Address: Department of Humanities, Social Sciences and Education, University of Molise, Via Francesco De Sanctis, 1, 86100 Campobasso, Italy. [laura. tommaso@unimol.it] 